\title{
Analysis on Wind Power Acceptance Ability Taking into Account Power System Economy
}

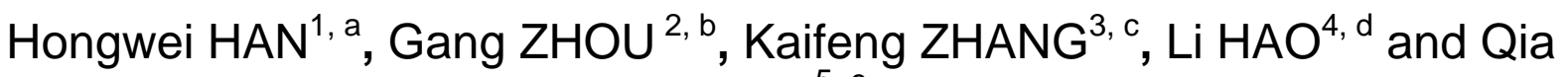 \\ DING ${ }^{5, e}$ \\ ${ }^{1}$ NINGXIA Electric Power Company Transportation Center, China \\ ${ }^{2}$ Key Laboratory of Measurement and Control of CSE School of Automation, Southeast University \\ Nanjing, China \\ ${ }^{3}$ NARI Group Corporation, Nanjing, China \\ axuschumi@163.com, bkevin_zhougang@163.com, kaifengzhang@seu.edu.cn, \\ dhaoli1226@sina.com, edingqia@sgepri.sgcc.com.cn
}

\begin{abstract}
Keywords: Wind power generation; Wind curtailment; Wind power acceptance ability; Surplus reserve capacity.

Abstract. In order to analyze the wind power acceptance ability of the power grid, the assessment model of the wind power acceptance ability which takes power system economy into consideration has been established in the paper. On account of the contradiction between the utilization of wind power and the power system economy, the multi-objective optimal dispatching model is established and the objective function is the utilization of wind power and the power system economy. The multi-objective problem is converted to the single objective problem and the scheduling scheme is made. Based on the dispatching scheme, the reserve capacity considering the load forecasting errors and units' accident rate is calculated. The IEEE 39-bus system is used to illustrate the proposed method. The simulation results verify the validity of the model.
\end{abstract}

\section{Introduction}

With the rapid development of the wind power in China, the influences caused by the variability and uncertainty of wind power are more and more obvious, which bring many problems to the safe and stable operation of the power system. In order to cope with the wind power fluctuations, the system economy is sacrificed due to the insufficient energy structure adjustment ability. Wind power curtailment conditions even occur when the wind power is excessive. With the increasing of the wind power penetration rate, it's difficult for the power grid to accept wind power. Hence, it is necessary to reasonably research on the wind power acceptance ability of the power system and the planning process of wind power farms, which is conducive to improve the utilization of wind power and realize the reliable, safe and economic operation of the power system.

Domestic and foreign scholars have conducted the deep research on the wind power acceptance ability from different perspectives. Based on the analysis of the power grid peak load regulation, the peak load regulation ability of power system that can provide guidance for developing planning of power system is analyzed [1]. Large-scale wind power integration into system brings huge influences to steady and dynamic operation of power system, and wind power acceptance ability is influenced by structure of power grid and distribution network [2, 3]. Reference [4] considered the fault probability of transmission components and analyzed the power grid parameters, power source parameters, and the load demand of the system. The relationship between the static security of grid $N-0, N-1$ and the wind power acceptance ability of power system are also revealed. The influencing factors of dynamic economic dispatching of power system containing wind farm were investigated in [5]. The total power generation costs, containing the thermal power unit valve point effect, were considered in the objective function to cut more generation cost. Reference [6] proposed the method of more wind power scenarios robust backup scheduling mode and economic operation mode, which can reduce the influences of the wind power uncertainty on the safety and economy in power system. 
The above-mentioned references mainly evaluate the wind power acceptance ability from the perspective of power grid, wind power itself and scheduling level. If only the wind power acceptance capacity is pursued, the system economy may be poor and it isn't conducive to realize value of wind power. According to the existing work, the wind power acceptance ability evaluation model considering system economy is established. The model includes the optimal scheduling model and wind power acceptance intervals model. The optimal scheduling model contains the two objectives of minimum wind curtailment capacity and the minimum system operation cost, which can get lower wind curtailment capacity and lower operation cost at same time. Moreover, the multi-objective problem is converted to the problem of single objective, so the scheduling scheme is made and the reserve capacity is calculated. Simulation results illustrate the validity of the model.

\section{Model of wind power acceptance ability considering power system economy}

Problem definition. System operation cost are usually set as the optimization objective in the traditional power system economic dispatching methods, which can effectively reduce the operation cost. However, single pursuit of the system economy will result in wind curtailment and lower utilization rate of wind power, and it is not conducive to realize value of wind power. Meanwhile, in order to maximize the wind power acceptance capacity, the outputs and conditions of units must be changed frequently to cope with the fluctuation of wind power, and it's inevitable to increase operation cost. Thus, contradiction between maximum wind power acceptance capacity and minimum power system economy is ineluctable, and it's sensible to balance wind curtailment capacity and operation cost. In this paper, the assessment model of the wind power acceptance ability which takes power system economy into consideration is established. Membership function is introduced to convert the multi-objective problem into single objective problem, which can balance wind power acceptance capacity and system economy effectively. The scheduling scheme can be made, and reserve capacity considering the load forecasting errors and units' accident rate can be calculated. The surplus reserve capacity is set as the intervals of the wind power acceptance to cope with the wind power fluctuation in this paper.

\section{Model formulation}

A. Optimal dispatching model considering wind power

The optimal objective is to minimize the wind curtailment of the power system and the minimum operation cost. The objective function (1) is wind curtailment of the power system. The objection function (2) is composed of fuel costs for producing electric power, startup and shutdown costs of individual units.

$$
\begin{aligned}
& \min P_{W, \text { Sum }}=\sum_{t=1}^{N T}\left(P_{W, t, \text { forecast }}-P_{W, t}\right) \\
& \min f_{\text {cost } t \text { sum }}=\sum_{t=1}^{N T} \sum_{i=1}^{N G}\left(f_{\mathrm{G} i, t}^{p}+f_{G i, t}^{o n}+f_{\mathrm{G} i, t}^{o f f}\right)
\end{aligned}
$$

where $N T$ is the number of periods $(24 \mathrm{~h}) . N G$ is the number of non-wind units. $P_{W, \text { Sum }}$ is wind curtailment. $P_{W, t, f o r e c a s t}$ is the wind power forecasting at time $t . P_{W, t}$ is the outputs of units at time $t$. $f_{\mathrm{G} i, t}^{p}$ is the generating cost of unit $i$ at time $t . f_{G i, t}^{o n}$ is the startup cost of unit $i$ at time $t, f_{\mathrm{G} i, t}^{o f f}$ is the shutdown cost of unit $i$ at time $t . f_{\mathrm{Gi}, t}^{p}, f_{G i, t}^{o n}$ and $f_{\mathrm{G} i, t}^{o f f}$ are shown in (3) (4) (5), respectively.

$$
\begin{aligned}
& f_{\mathrm{G} i, t}^{p}=\left(a_{2 i} P_{G i, t}{ }^{2}+a_{1 i} P_{G i, t}+a_{0 i}\right) \mu_{i, t} \\
& f_{G i, t}^{o n}=f_{i, \cos t}^{o n} \cdot \mu_{i, t}\left(1-\mu_{i, t-1}\right) \\
& f_{G i, t}^{o f f}=f_{i, \cos t}^{o n} \cdot \mu_{i, t-1}\left(1-\mu_{i, t}\right)
\end{aligned}
$$


where $P_{G i, t}$ is the generation of unit $i$ at time $t, a_{0 i}, a_{1 i}$ and $a_{2 i}$ are the parameters of operation costs. $f_{i, \text { cos } t}^{o n}$ is the startup and shutdown cost of unit $i$ at time $t, \mu_{i, t}$ is the condition of unit $i$ at time $t, \mu_{i, t-1}$ is the generation of unit $i$ at time $t-1$ 。

The constraints listed below include the system power balance constraints (6), units generation limits (7), units ramping up limits (8), system operating reserve requirements (9), units minimum ON time and OFF time limits (10), line power flow restriction (11), and wind power generation constraints (12). The optimal model is to minimize the wind curtailment of the power system, so the wind power generation should be less than the wind power forecasting results (13).

$$
\begin{aligned}
& \sum_{i=1}^{N G} P_{G i, t}+P_{W, t}=P_{L, t}+P_{\text {line }, t} \quad(t=1, \ldots, N T) \\
& P_{G i}^{\min } \mu_{i, t} \leq P_{G i, t} \leq P_{G i}^{\max } \mu_{i, t} \quad(t=1, \ldots, N T) \\
& \left\{\begin{array}{l}
P_{G i, t}-P_{G i, t-1} \leq \Delta P_{G i}^{u p} \\
P_{G i, t-1}-P_{G i, t} \leq \Delta P_{G i}^{d n}
\end{array} \quad(i=1, \ldots, N G ; t=1, \ldots, N T)\right. \\
& \left\{\begin{array}{l}
\sum_{i=1}^{N G}\left(P_{G i, t}-P_{G i}^{\min }\right) \mu_{i, t} \geq \lambda_{1} P_{L, t}+\lambda_{2} P_{W, t} \quad(t=1, \ldots, N T) \\
\sum_{i=1}^{N G}\left(P_{G i}^{\max }-P_{G i, t}\right) \mu_{i, t} \geq \lambda_{1} P_{L, t}+\lambda_{2} P_{W, t}
\end{array}\right. \\
& \left\{\begin{array}{l}
\left(X_{i, t, 1}^{o n}-T_{i}^{o n}\right) \cdot\left(\mu_{i, t-1}-\mu_{i, t}\right) \geq 0 \\
\left(X_{i, t-1}^{\text {off }}-T_{i}^{\text {off }}\right) \cdot\left(\mu_{i, t}-\mu_{i, t-1}\right) \geq 0
\end{array} \quad(i=1, \ldots, N G ; t=1, \ldots, N T)\right. \\
& P_{\text {flow, }, l, t} \leq P_{\text {flow,l }}^{\max }(t=1, \ldots, N T) \\
& 0 \leq P_{W, t} \leq P_{W}^{\max }(t=1, \ldots, N T) \\
& 0 \leq P_{W, t} \leq P_{W, t, f \text { forecast }}(t=1, \ldots, N T)
\end{aligned}
$$

where $P_{L, t}$ and $P_{\text {line, }}$ are system load demand and system loss at time $t$, respectively. $P_{G i}^{\min }$ and $P_{G i}^{\max }$ are the lower limit and the upper limit power generation of unit $i$, respectively. $P_{G i, t-1}$ is the power generation of unit $i$ at time $t-1 . \Delta P_{G i}^{u p}$ and $\Delta P_{G i}^{d n}$ are the ramp rate limit and down rate limit of unit $i$, respectively. $\lambda_{1}$ is the coefficient of load reserve, $\lambda_{2}$ is the coefficient of wind power reserve. $X_{i, t-1}^{o n}$ and $X_{i, t-1}^{o f f}$ are ON time and OFF time of unit $i$ at time $t-1$, respectively. $T_{i}^{o n}$ and $T_{i}^{\text {off }}$ are the minimum ON time and OFF time of unit $i$, respectively. $P_{\text {flow, }, t,}$ is DC power flow of transmission line $l$ at time $t . P_{\text {flow }, l}^{\max }$ is the DC power flow limit of transmission line $l$ at time $t . P_{W}^{\max }$ is system wind farm installed capacity. $P_{W, t, f o r e c a s t}$ is wind power forecasting outputs.

B. Model of wind power acceptance intervals

Based on the optimal dispatching model, the scheduling scheme are made uniquely, so the main factors that can cope with uncertainty of wind power are surplus reserve capacity of power system, and nonconventional approaches, such as wind power curtailment and load-shedding. Therefore, after the scheduling scheme of power system is made, the wind power acceptance capacity of power system at time $t$ depends on the surplus reserve capacity of power system. The surplus reserve capacity is the total reserve capacity minus the reserve capacity in the load forecasting errors and units' accident rate. Amount of reserve capacity should be prepared to cope with the uncertainty of wind power. Therefore, the down-regulation surplus reserve capacity can be used to reply to upward fluctuation of wind power. Contrarily, the up-regulation surplus reserve capacity can deal with the downward fluctuation of wind power. The surplus up-regulation and down-regulation reserve capacity at time $t$ are shown in (14) (15), and equation (16) is the wind power acceptance intervals in the scheduling scheme. 


$$
\begin{gathered}
\left\{\begin{array}{l}
R_{R s u m, t}^{u p}=R_{\text {sum }, t}^{u p}-R_{\text {load }, t}-R_{\text {oveh }} \\
R_{\text {Rsum }, t}^{d n}=R_{\text {sum }, t}^{d n}-R_{\text {load }, t}-R_{\text {oveh }}
\end{array}\right. \\
\text { (14) }\left\{\begin{array}{l}
R_{R s u m, t}^{u p}=\Delta P_{W, t}^{d n}+\lambda_{2} \Delta P_{W, t}^{d n} \\
R_{R s u m, t}^{d n}=\Delta P_{W, t}^{u p}+\lambda_{2} \Delta P_{W, t}^{u p}
\end{array}\right. \\
\left\{\begin{array}{l}
P_{W, t}^{u p}=P_{W, t}+\Delta P_{W, t}^{u p}=P_{W, t}+\frac{R_{R \text { sum }, t}^{d n}}{1+\lambda_{2}} \\
P_{W, t}^{d n}=P_{W, t}+\Delta P_{W, t}^{d n}=P_{W, t}+\frac{R_{R s u m, t}^{u p}}{1+\lambda_{2}}
\end{array}\right.
\end{gathered}
$$

where $R_{R s u m, t}^{u p}$ and $R_{R s u m, t}^{d n}$ are surplus up-operation and down-operation reserve capacity at time $t$, respectively. $R_{\text {load }, t}$ is load reserve capacity at time $t . R_{\text {oveh }}$ is reserve capacity for units emergency and overhaul at time $t$. $R_{\text {sum }, t}^{u p}$ and $R_{\text {sum }, t}^{d n}$ are total up-operation are down-operation reserve capacity at time $t$, respectively. $\Delta P_{W, t}^{u p}$ and $\Delta P_{W, t}^{d n}$ are the upper limit and the lower limit of wind power fluctuation at time $t$, respectively. $\lambda_{2}$ is reserve coefficient of wind power, equaling to 0.5 in this paper. $P_{W, t}$ is wind power outputs at time $t$ in this scheduling scheme. $P_{W, t}^{u p}$ and $P_{W, t}^{d n}$ are the upper limit and he lower limit of wind power acceptance intervals, respectively.

Model solving. Considering power system economy, the optimal model of the wind power acceptance ability is established, which includes two objective function of wind curtailment and operation cost in the power system. Based on fuzzy set theory and the maximum satisfaction degree method, the multi-objective optimal dispatching model is converted to single-objective problem by introducing the membership function of wind curtailment and operation cost. Lower semi-trapezoidal distribution is used to express the membership function of wind curtailment and operation cost (17) (18). ${ }^{[7,8]}$

$$
\begin{aligned}
& \mu\left(f_{\cos t, \text { sum }}\right)= \begin{cases}1 & f_{\cos t, \text { sum }} \leq f_{\cos t, \text { sum }}^{\min } \\
\frac{f_{\cos t, \text { sum }}^{\max }-f_{\cos t, \text { sum }}}{f_{\cos t, \text { sum }}^{\max }-f_{\cos t, \text { sum }}^{\min }} & f_{\text {cos } t, \text { sum }}^{\min } \leq f_{\cos t, \text { sum }} \leq f_{\cos t, \text { sum }}^{\max } \\
0 & f_{\cos t, \text { sum }} \geq f_{\cos t, \text { sum }}^{\max }\end{cases} \\
& \mu\left(P_{W, \text { sum }}\right)=\left\{\begin{array}{lc}
1 & P_{W, \text { sum }} \leq P_{W, \text { sum }}^{\min } \\
\frac{P_{W, \text { sum }}^{\max }-P_{W, \text { sum }}}{P_{W, \text { sum }}^{\max }-P_{W, \text { sum }}^{\min }} & P_{W, \text { sum }}^{\min } \leq P_{W, \text { sum }} \leq P_{W, \text { sum }}^{\max } \\
0 & P_{W, \text { sum }} \geq P_{W, \text { sum }}^{\max }
\end{array}\right.
\end{aligned}
$$

where $\mu\left(f_{\text {cost } t \text { sum }}\right)$ is the satisfaction degree of system operation cost $f_{\text {cost } t \text { sum }} . f_{\text {cost }, \text { sum }}^{\max }$ and $f_{\text {cost } t \text { sum }}^{\min }$ are the upper limit and lower limit of optimal objective respectively. $\mu\left(P_{W, \text { sum }}\right)$ is the satisfaction degree of the wind curtailment capacity $P_{W, \text { sum }} . P_{W \text {,sum }}^{\max }$ and $P_{W, \text { sum }}^{\min }$ are upper limit and lower limit of optimal objective respectively. The membership functions of operation cost and wind curtailment capacity are shown in Fig. 1 and Fig. 2, respectively. 


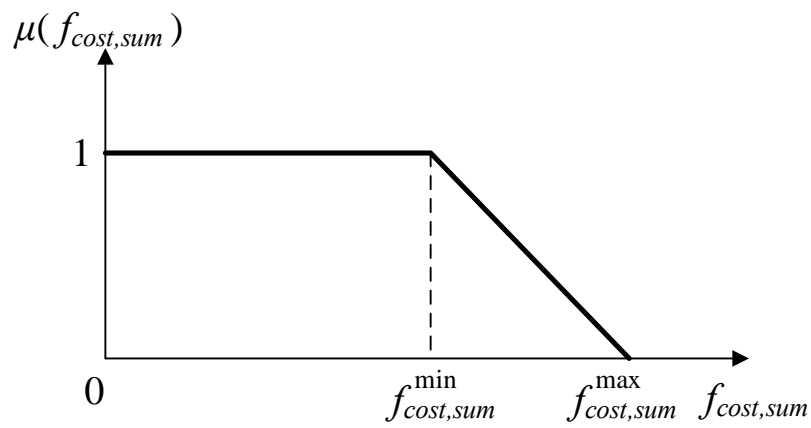

Fig. 1. The membership function of operation cost

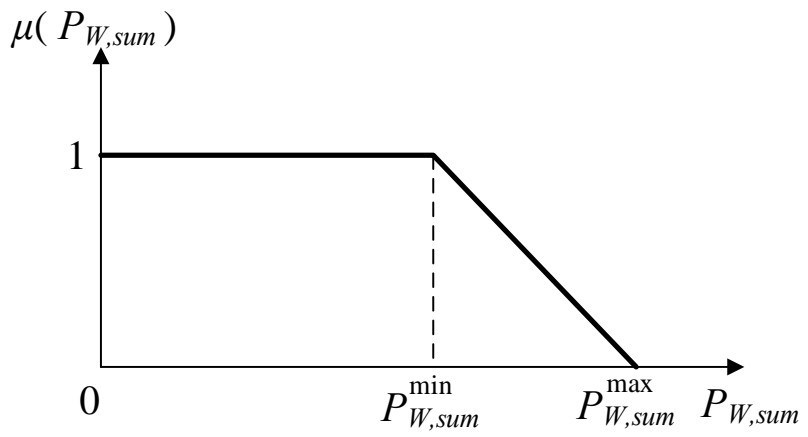

Fig. 2. The membership function of wind curtailment capacity

Once the membership function of the wind curtailment and operation cost is built, $\mu_{\min }$ is supposed to be the minimum of the membership function in the optimal objection, which can express overall satisfaction of the model (19). Therefore, the multi-objective optimization problem is converted to a single objective optimization problem which satisfies the overall satisfaction $\mu_{\min }$ of all the constraints.

$$
\mu_{\text {min }}=\min \left\{\mu\left(f_{\text {cost }, \text { sum }}\right), \mu\left(P_{W, \text { sum }}\right)\right\}
$$

The operation cost and units ON and OFF time limits in the model can be linearized according to method [9]. Hence, the optimization model is converted to a mixed-integer linear optimization problem. After the dispatching scheme is made, the reserve capacity considering the load forecasting errors and units' accident rate can be calculated. The surplus reserve capacity are set as the intervals of the wind power acceptance to cope with the wind power fluctuation. The flowchart of the proposed method is shown in Fig. 3.

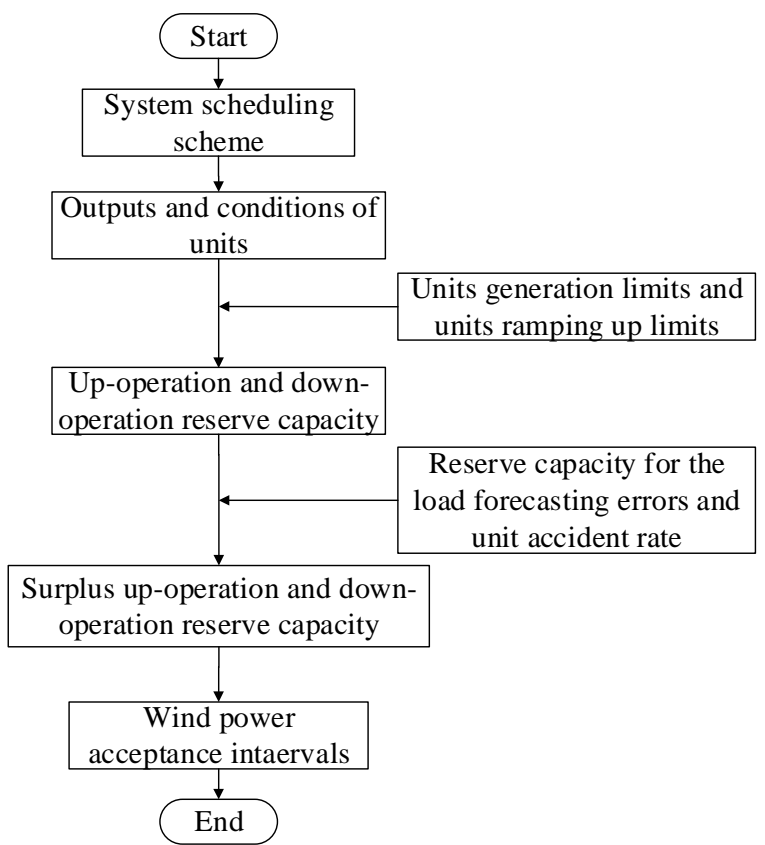

Fig. 3. The flowchart of the proposed method 


\section{Case study}

An IEEE 39-bus system, as shown in Fig. 4, is used to test the proposed method which considers the unit commit in 24 hours, and illustrates the feasibility of the proposed model. Operation parameters of the thermal units, data of load forecasting, load distribution ratio of each load and branch information are from Ref. [10]. In this case, the overall load capacity is $300 \mathrm{MW}$ and the wind farm capacity installed in node 14 is $700 \mathrm{MW}$. The wind power forecasting capacity is shown in Table 1.

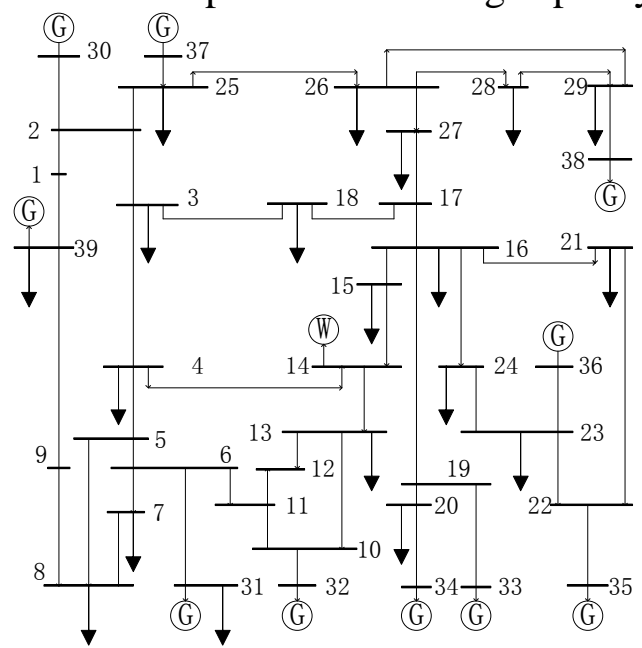

Fig. 4. IEEE 39-bus system

Table 1 . Wind power forecasting capacity

\begin{tabular}{cc|cc}
\hline Time(h) & Wind power capcacity(MW) & Time(h) & Wind power capacity(MW) \\
\hline 1 & 150 & 13 & 240 \\
2 & 130 & 14 & 230 \\
3 & 120 & 15 & 220 \\
4 & 130 & 16 & 205 \\
5 & 155 & 17 & 190 \\
6 & 175 & 18 & 185 \\
7 & 190 & 19 & 180 \\
8 & 210 & 20 & 175 \\
9 & 230 & 21 & 185 \\
10 & 245 & 22 & 180 \\
11 & 250 & 23 & 190 \\
12 & 248 & 24 & 180 \\
\hline
\end{tabular}

The single-objective function (1) is set as the optimal objective to calculate the maximum operation cost $f_{\text {cost }, \text { sum }}^{\max }$ and minimum operation cost $f_{\text {cost,sum }}^{\min }$. The single-objective function (2) is used to calculate the maximal and minimal wind power acceptance capacity $P_{W, \text { sum }}^{\max }$ and $P_{W \text {,sum }}^{\min }$. The single-objective optimal results are shown in Table 1 . The multi-objective optimal results are shown in Table 3.

Table 2. Single-objective function optimization results

\begin{tabular}{c|c|c|c|c}
\hline $\begin{array}{c}\text { Optimizatio } \\
\mathrm{n}\end{array}$ & \multicolumn{2}{|c|}{$P_{W, \text { sum }}(\mathrm{MW})$} & \multicolumn{2}{c}{$f_{\text {cost }, \text { sum }}(\$)$} \\
\cline { 2 - 5 } objective & $\operatorname{Min}\left(P_{W, \text { sum }}\right)$ & $\operatorname{Max}\left(P_{W, \text { sum }}\right)$ & $\operatorname{Min}\left(f_{\text {cost }, \text { sum }}\right)$ & $\operatorname{Max}\left(f_{\text {cost }, \text { sum }}\right)$ \\
\hline$P_{W, \text { sum }}(\mathrm{MW})$ & 226.38 & 4439.5 & 4159.71 & 226.38 \\
$f_{\text {cost }, \text { sum }}(\$)$ & 664409 & 543713 & 483162 & 686626 \\
\hline
\end{tabular}

Table 3. Multiple-objective function optimization results

\begin{tabular}{ccc}
\hline Optimization objective & $P_{W, \text { sum }}(\mathrm{MW})$ & $f_{\text {cost }, \text { sum }}(\$)$ \\
\hline $\operatorname{Min}\left(P_{W, \text { sum }}, f_{\text {cost }, \text { sum }}\right)$ & 4415 & 486817
\end{tabular}

Comparison between single and multiple optimal results are shown as follow: 1) Considering the operation cost of the power system, the capacity of the total wind power acceptance capacity are 
reduced $\Delta P_{W, \text { sum }}^{-}=24.5(\mathrm{MW})$ and the operation cost reduces by $\Delta f_{\text {cost } t \text { sum }}^{-}=56896(\mathrm{MW})$. As can be seen, the wind power acceptance capacity doesn't achieve the maximum and the operation of power system is reduced greatly. 2) Considering the wind power acceptance capacity, the power system operation cost will grow by $\Delta f_{\text {cost } t \text { sum }}^{+}=3655(\mathrm{MW})$ and the wind power acceptance capacity of power system has increased by $\Delta P_{W, \text { sum }}^{+}=255.3(\mathrm{MW})$. The assessment model of the wind power acceptance ability balances maximum wind power acceptance capacity $P_{W, \text { sum }}$ and minimum system operation cost $f_{\text {cost } t \text { sum }}$ effectively. Both security and economy operation of the power system can be achieved, so the scheduling scheme can be made in Table 4.

Table 4. The scheduling scheme considering wind power acceptance ability

\begin{tabular}{ccccccccccc}
\hline Time(h) & U1 & U2 & U3 & U4 & U5 & U6 & U7 & U8 & U9 & U10 \\
\hline 1 & 99 & 0 & 100 & 100 & 61 & 20 & 0 & 0 & 0 & 20 \\
2 & 100 & 0 & 100 & 100 & 64 & 38 & 0 & 0 & 0 & 43 \\
3 & 100 & 0 & 100 & 100 & 69 & 68 & 0 & 0 & 0 & 68 \\
4 & 100 & 25 & 100 & 100 & 75 & 72 & 0 & 0 & 0 & 74 \\
5 & 100 & 35 & 100 & 100 & 77 & 65 & 0 & 0 & 0 & 67 \\
6 & 100 & 60 & 100 & 100 & 83 & 52 & 0 & 0 & 0 & 80 \\
7 & 100 & 67 & 93 & 100 & 86 & 24 & 0 & 25 & 10 & 80 \\
8 & 100 & 66 & 62 & 100 & 82 & 20 & 0 & 55 & 25 & 80 \\
9 & 100 & 84 & 27 & 100 & 78 & 27 & 0 & 85 & 40 & 80 \\
10 & 100 & 85 & 23 & 100 & 100 & 57 & 0 & 85 & 55 & 80 \\
11 & 100 & 85 & 52 & 100 & 100 & 68 & 0 & 85 & 55 & 80 \\
12 & 100 & 85 & 87 & 100 & 100 & 50 & 25 & 85 & 55 & 80 \\
13 & 100 & 85 & 52 & 100 & 87 & 20 & 25 & 85 & 55 & 80 \\
14 & 100 & 82 & 20 & 100 & 88 & 0 & 25 & 85 & 40 & 80 \\
15 & 100 & 57 & 49 & 100 & 88 & 0 & 0 & 80 & 25 & 80 \\
16 & 100 & 32 & 84 & 100 & 73 & 0 & 0 & 50 & 10 & 71 \\
17 & 100 & 26 & 100 & 100 & 77 & 0 & 0 & 26 & 0 & 80 \\
18 & 100 & 44 & 100 & 100 & 83 & 20 & 0 & 38 & 0 & 80 \\
19 & 100 & 48 & 100 & 100 & 88 & 50 & 0 & 55 & 0 & 79 \\
20 & 100 & 73 & 100 & 100 & 100 & 78 & 0 & 85 & 10 & 80 \\
21 & 100 & 50 & 85 & 100 & 94 & 74 & 0 & 85 & 0 & 80 \\
22 & 100 & 25 & 100 & 100 & 82 & 44 & 0 & 55 & 0 & 64 \\
23 & 100 & 0 & 96 & 100 & 58 & 20 & 0 & 25 & 0 & 61 \\
24 & 100 & 0 & 100 & 100 & 66 & 0 & 0 & 0 & 0 & 54 \\
\hline & & & & & & & & & &
\end{tabular}

Based on the scheduling scheme, capacity of integrated wind power, up-regulation and down-regulation reserve capacity can be calculated. Results are shown in Table 5 and Table 6 . The paper assumes that the sum of load reserve capacity, emergency reserve capacity and overhaul reserve capacity are five percent of system load capacity, that is $R_{\text {load }, t}+R_{\text {oveh }}=0.05 P_{L, t}$.

Table 5. Capacity of integrated wind power

\begin{tabular}{cc|cc}
\hline Time(h) & Wind power(MW) & Time(h) & Wind power(MW) \\
\hline 1 & 150 & 13 & 211.1 \\
2 & 130 & 14 & 230 \\
3 & 120 & 15 & 220 \\
4 & 130 & 16 & 205 \\
5 & 155 & 17 & 190 \\
6 & 175 & 18 & 185 \\
7 & 190 & 19 & 180 \\
8 & 210 & 20 & 175 \\
9 & 230 & 21 & 182.19 \\
10 & 215.06 & 22 & 180 \\
11 & 199.3 & 23 & 190 \\
12 & 182.7 & 24 & 180 \\
\hline
\end{tabular}


Table 6. Up-regulation and down-regulation reserve capacity

\begin{tabular}{ccc|ccc}
\hline $\begin{array}{c}\text { Time } \\
\text { (h) }\end{array}$ & $\begin{array}{c}\text { Up-operation reserve } \\
\text { capacity(MW) }\end{array}$ & $\begin{array}{c}\text { Down-operation } \\
\text { reserve capacity(MW) }\end{array}$ & $\begin{array}{c}\text { Time } \\
\text { (h) }\end{array}$ & $\begin{array}{c}\text { Up-operation reserve } \\
\text { capacity(MW) }\end{array}$ & $\begin{array}{c}\text { Down-operation } \\
\text { reserve capacity(MW) }\end{array}$ \\
\hline 1 & 282.6 & 220.51 & 13 & 260.08 & 196.59 \\
2 & 128.01 & 165.14 & 14 & 202.42 & 193.38 \\
3 & 113.01 & 224.32 & 15 & 151.61 & 184.05 \\
4 & 115.12 & 210.43 & 16 & 223.92 & 168.43 \\
5 & 145.65 & 194.96 & 17 & 196.55 & 198.65 \\
6 & 134.64 & 237.96 & 18 & 138.01 & 199.34 \\
7 & 183.94 & 202.46 & 19 & 147.2 & 244.08 \\
8 & 207.08 & 198.86 & 20 & 106.97 & 334.37 \\
9 & 196.83 & 258.51 & 21 & 167.74 & 212.81 \\
10 & 115.53 & 278.31 & 22 & 244.02 & 162.19 \\
11 & 110.24 & 273.18 & 23 & 266.95 & 144.04 \\
12 & 123.02 & 277.92 & 24 & 129.71 & 159.02 \\
\hline
\end{tabular}

The wind power acceptance intervals considering power system economy are calculated according to equation (14) (15) and (16), as shown in Table 7. In order to present the wind power acceptance ability, the installed capacity of the wind power isn't taken into account and only the wind power acceptance intervals are calculated.

Table 7. The upper and lower limits of the wind power acceptance intervals.

\begin{tabular}{ccc|ccc}
\hline Time(h) & Upper limit(MW) & Lower limit(MW) & Time(h) & Upper limit(MW) & Lower limit(MW) \\
\hline 1 & 278.68 & 0 & 13 & 312.16 & 67.71 \\
2 & 220.93 & 63.38 & 14 & 330.58 & 123.39 \\
3 & 248.72 & 65.49 & 15 & 316.03 & 145.59 \\
4 & 247.78 & 75.75 & 16 & 293.12 & 79.89 \\
5 & 261.64 & 81.23 & 17 & 299.1 & 82.3 \\
6 & 308.64 & 110.24 & 18 & 292.89 & 117.99 \\
7 & 299.14 & 93.21 & 19 & 316.05 & 108.53 \\
8 & 315.9 & 98.61 & 20 & 367.91 & 133.68 \\
9 & 374 & 127.11 & 21 & 295.73 & 98.69 \\
10 & 370.6 & 168.04 & 22 & 263.13 & 42.32 \\
11 & 350.58 & 156.64 & 23 & 264.36 & 33.7 \\
12 & 336.32 & 132.36 & 24 & 266.02 & 113.52 \\
\hline
\end{tabular}

Fig. 5 shows the wind power acceptance and the corresponding acceptance intervals. The wind power acceptance intervals are "complete intervals" in the scheduling scheme, which means wind power fluctuating in the intervals can be accepted completely. The scheduling scheme is based on safety and economy of power system because the model balances both the maximum wind power acceptance capacity and the minimum system operation cost. If the wind power generation isn't in the acceptance intervals at time $t: P_{W, t}^{u p} \leq P_{W, t}, P_{W, t} \leq P_{W, t}^{d n}$, the measures, such as wind curtailment or load shedding, must be used in wind power generation. If the wind power generation is in the acceptance intervals at time $t: P_{W, t}^{d n} \leq P_{W, t} \leq P_{W, t}^{u p}$, the surplus reserve capacity is adequate enough to solve the wind generation fluctuation and the wind power can be accepted completely at this time. 


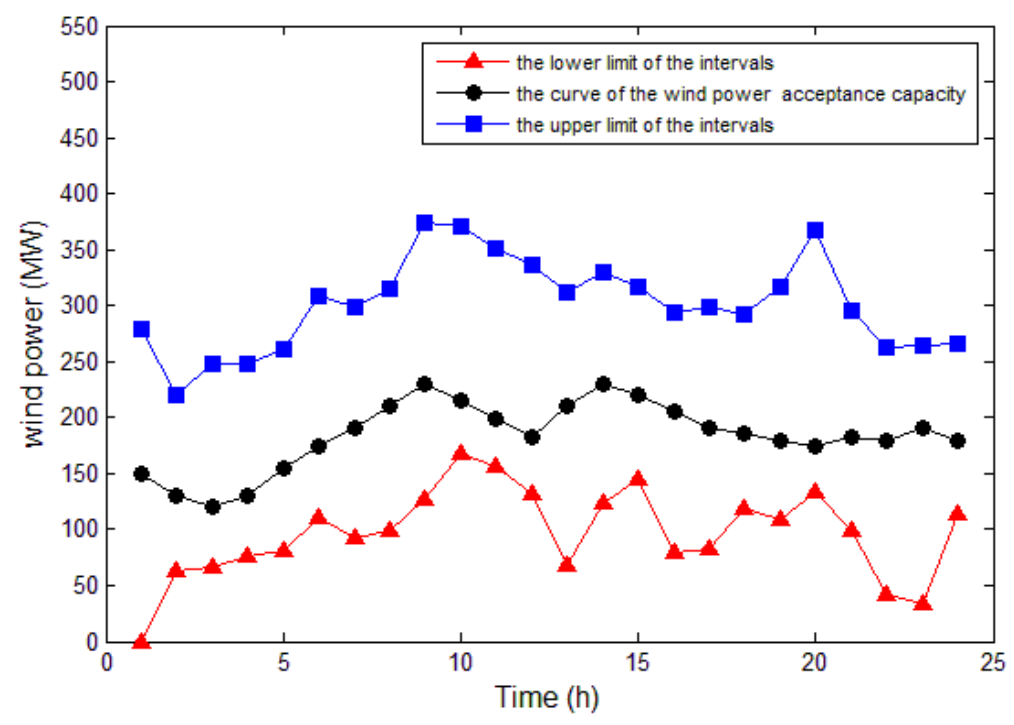

Fig. 5. Wind power acceptance intervals

\section{Conclusion}

This paper established the model of wind power acceptance ability which considers the power system economy, and analyzed wind power acceptance ability of power system. The dispatching model is a multi-objective problem, which balances both maximum wind power acceptance capacity and minimum system operation cost. Moreover, the membership function is introduced and the multi-objective problem is converted to the single objective problem. The corresponding scheduling scheme is made. Based on the scheduling scheme, the reserve capacity considering the load forecasting errors and units' accident rate is calculated. Then the surplus reserve capacity are set as the intervals of the wind power acceptance. The IEEE 39-bus test system is used to analyze the proposed methodology. The simulation results illustrate the rationality and validity of the model, which is very significanct to improve the utilization of the wind power and guarantees the safety and economy of the power system.

\section{Acknowledgements}

This work was financially supported by Program National Natural Science Foundation of China (No. 51177019, No. 51577031 and No. 51477157) and Program of State Grid Corporation of China (Research of the Key Technique for Large-scale New Energy Integration Dispatching Plan and Security Correction based on Probability Analysis, No. 8508000149).

\section{References}

[1] Jinxiong YAO, Shiqiang ZHANG. Analysis on Capacity of Wind Power Integration into Grid Based on Peak Load Regulation[J]. Power System and Clean Energy, 2010, 07: 25-28. "In Chinese”.

[2] Roy N K, Pota H R, Hossain M J, et al. Impact of SCIG and DFIG type wind turbine on the stability of distribution networks: Static and dynamic aspects[C]//EEE 11th International Conference on Environment and Electrical Engineering (EEEIC), 2012: 543-548.

[3] Zaininger H W, Bell D J. Potential dynamic impacts of wind turbines on utility systems[J]. IEEE Transactions on Power Apparatus and Systems, 1981 (12): 4821-4829. 
[4] Hao ZHA, Wenhui SHI. Study on power grid probabilistic optimal dispatch of coordinating wind power accommodation capability[J]. Power System Protection and Control, 2012, 22: 14-18. "In Chinese”.

[5] Wei ZHOU, Yu PENG, Hui SUN. Dynamic Economic Dispatch in Wind Power Integrated System[J]. Proceedings of the CSEE, 2009, 25: 13-18. "In Chinese".

[6] Qiushi XU, Changhong DENG, Weixin ZHAO. A Multi-Scenario Robust Dispatch Method for Power Grid Integrated With Wind Farms[J]. Power System Technology, 2014, 03: 653-661. "In Chinese”.

[7] Guojun XIAO, Renun ZHOU, Suping WU. Security Economic Dispatch in Wind Power Integrated Systems Using an Interactive Decision Making Method[J]. Electrical Engineering, 2013, 04: 1-5+10. “In Chinese”.

[8] Haiyan CHEN, Jinfu CHEN, Xianzhong DUAN. Fuzzy Modeling and Optimization Algorithm on Dynamic Economic Dispatch in Wind Power Integrated System[J]. Automation of Electric Power Systems, 2006, 02: 22-26. "In Chinese”.

[9] Madrigal M, Quintana V H. Semidefinite programming relaxations for $\{0,1\}$-power dispatch problems[C]//IEEE Power Engineering Society Summer Meeting, 1999, 2: 697-702.

[10] Lizi ZHANG, Feng LI, etc. Optimal Reserve Dispatch Approach Considering Wind Power And Load Fluctuations And N-1 Fault[J]. Acta Energiae Solaris Sinica, 2014, 01: 64-73.“In Chinese”. 